DOI: http://dx.doi.org/10.18203/2320-1770.ijrcog20193774

Original Research Article

\title{
Neuro-imaging study in eclampsia
}

\author{
Sujata Swain ${ }^{1 *}$, Paresh Kumar Jena ${ }^{2}$
}

\begin{abstract}
${ }^{1}$ Department of Obstetrics and Gynaecology, S. C. B. Medical College, Cuttack, Odisha, India
\end{abstract}
${ }^{2}$ Department of Internal Medicine, Kalinga Hospital, Bhubaneswar, Odisha, India

Received: 20 September 2018

Accepted: 22 October 2018

\section{*Correspondence:}

Dr. Sujata Swain,

E-mail: drsujata74@gmail.com

Copyright: () the author(s), publisher and licensee Medip Academy. This is an open-access article distributed under the terms of the Creative Commons Attribution Non-Commercial License, which permits unrestricted non-commercial use, distribution, and reproduction in any medium, provided the original work is properly cited.

\begin{abstract}
Background: Eclampsia is associated with increased risk of maternal death varying from $1.8 \%$ in developed countries to $14 \%$ in developing countries. Cerebral complications are the major cause of death in eclampsia patients. Eclampsia along with hypercoagulopathy of pregnancy is a high risk fact for patient in respect of development of cerebrovascular thrombosis/haemoorhage. Eclampsia patients have been found to have various CNS pathological conditions amenable to the medical treatment. The aim of the study is to know the neuropathophysiology behind an eclamptic seizure to reduce the morbidity associated with it.

Methods: Prospective study design included 50 patients for the study. All patients were admitted in the eclampsia room with h/o convulsions. All patients were put on $\mathrm{MgSO}_{4}$ therapy and anti-hypertensive. Cranial CT scan examinations were performed for all patients within 24hours of last convulsion without intravenous contrast material injection. Time taken to recover from all the clinical symptoms like altered consciousness, defective vision, headache and seizure and the maternal outcome are compared.

Results: $62 \%$ of patients with eclampsia had detectable pathological changes in CT scan. Cerebral edema was the most common CT scan finding with parietal lobe was the most common site $(90.32 \%)$ of pathological changes. Mortality rate was high among eclamptic patients with cerebral hemorrhage.

Conclusions: CT scan was found to be effective in detecting cerebral pathology in more than half of the eclamptic patients. The most common pathological changes detected are cerebral edema and cerebral infarction. CT scan may not be required for the diagnosis of eclampsia, but it must be used in certain complicated patients to detect cerebral pathology at the earliest so that specific management could be provided to reduce the maternal mortality.
\end{abstract}

Keywords: Cerebral edema, Convulsions, CT scan, Eclampsia, Maternal mortality

\section{INTRODUCTION}

Eclampsia is defined as occurrence of one or more convulsions in pregnant woman with hypertension and proteinuria that cannot be attributed to any other cause. The word eclampsia is derived from Greek word meaning flash of lightening. In developing countries like India, eclampsia leads to complications in about 1-100 out of
1700 deliveries. Cerebral complications are the major cause of deaths in eclampsia patients, but the neuropathophysiology of eclamptic seizure still remain undiscovered. ${ }^{1}$

Eclampsia itself along with hypercoagulopathy of pregnancy is a high risk factor for development of CVTS and intracranial haemorrhage. ${ }^{2-6}$ Although eclampsia 
affects variety of organs, cerebrovascular involvement is the major cause of death in eclampsia patients. ${ }^{4-6}$

There has been considerable debate as to whether the neurological symptoms of eclampsia arise from the over autoregulation that causes vasospasm and ischaemia OR from hyperperfusion that causes cerebral oedema formation. $^{7}$ To describe neurological involvement in eclampsia, two theories have been proposed. ${ }^{6}$

\section{Theory of vasospasm}

In severe hypertension as in eclampsia, cerebral autoregulation comes into play which causes cerebral vasoconstriction. This vasospasm is believed to cause local anoxic damage to endothelium of capillaries and disruption of blood brain barrier, which leads to cerebral oedema.

\section{Forced dilation theory}

Sudden fluctuation in blood pressure exerts greater pressure on capillary walls and leads to extravasations of proteins and fluids: pericapillary ring haemorrhages.

Most common finding on CT scan in eclampsia patient is generalised cerebral oedema and features suggestive of hypertensive encephalopathy shows edema in the subcortical white matter and cortex that predominantly involves the occipital lobes with occasional involvement of parietal lobe, brain stem and basal ganglia. ${ }^{8}$ Neuroimaging can be very helpful in eclampsia patients who do not respond to conventional treatment with $\mathrm{MgSO}_{4}$ and antihypertensive. ${ }^{4}$

CT scan findings in eclampsia patient have found mainly transient cortical and subcortical white matter hypodensities which could be due to hypoxia or oedema. ${ }^{9}$ These lesions correspond to mainly watershed areas of circulation where anterior, middle and posterior cerebral arteries meet. It is in this area where the earliest breakthrough in autoregulation occurs. ${ }^{4,7}$ Other neuroimaging findings detected at times are cerebral venous thrombosis, intracerebral haemorrhage and infarction. Intracerebral haemorrhage is the most common cause of maternal death in eclampsia.

\section{METHODS}

This study was conducted in Obstetrics and Gynaecology Department of SCB Medical College, Cuttack during the period extending from September 20015 to September 2017. A total 43,634 numbers of patients were admitted to hospital through labour room for delivery or pregnancy related complications during the above period out of which 462 cases were eclamptic.

Depending upon the inclusion and exclusion criteria, 50 cases were included in the study. Approval of the Ethical
Committee of SCB Medical College, Cuttack has been taken to carry out the study.

Diagnosis of eclampsia was made on the basis of convulsion at gestational period of 28 weeks or more with raised blood pressure more than $140 / 90 \mathrm{mmHg}$ and proteinuria with/without edema.

Detail histories regarding the onset, number of convulsions, loss of consciousness were taken. General examination was made with reference to degree of consciousness, nutritional status, presence of pallor, edema, temperature, pulse rate, blood pressure.

Systemic examination of nervous, respiratory and cardiovascular system was done followed by abdominal examination with regard to height of uterus, lie, presentation, position of the fetus, assessment of liquor amnii and auscultation of fetal heart sound. Routine examination of hemoglobin, total platelet count, malaria parasite, urine albumin, blood grouping, Rhtyping, RFT, LFT and blood uric acid were carried out. $\mathrm{MgSO}_{4}$ regimen (Pritchard) started to control convulsion. Measures were taken to control blood pressure.

Cranial CT scan examinations were performed for all patients within 24 hours of last convulsion without intravenous contrast material injection. Clinical and laboratory data of all patients, with or without pathological findings on cranial CT scan were compared statistically.

Follow up of the patients done. Time taken to recover from all the clinical symptoms like altered consciousness, defective vision, headache and seizure and the maternal outcome are compared statistically in both groups with or without CT scan findings and with the type of lesions in positive finding cases.

\section{RESULTS}

Eclampsia was found to be more common among young pregnant women of age group $20-24$ years $(70 \%)$ and mostly in primigravida (74\%) (Table 1).

Common mode of termination of pregnancy of eclampsia patients in the hospital was found to be vaginal delivery (76\%) with/without instrumentation.44\% eclamptic women delivered vaginally spontaneously and $32 \%$ women required forceps/vacuum application. $22 \%$ delivery was done by LSCS (Table 1).

$62 \%$ of patients with eclampsia had detectable pathological changes in CT scan. It was positive in all cases with intrapartum eclampsia, $55.17 \%$ in APE and $62 \%$ in PPE (Table 2). 
Table 1: Distribution of eclampsia.

\begin{tabular}{|c|c|c|c|}
\hline \multicolumn{2}{|c|}{ Contributing factors } & $\begin{array}{l}\text { No. of } \\
\text { cases }\end{array}$ & $\begin{array}{l}\text { Percentage } \\
\text { of incidents }\end{array}$ \\
\hline \multirow{2}{*}{ Age } & 20-24 weeks & 35 & 70 \\
\hline & 25-29 weeks & 13 & 26 \\
\hline \multirow{2}{*}{ Gravidity } & Primi & 37 & 74 \\
\hline & Multi & 13 & 26 \\
\hline \multirow{2}{*}{$\begin{array}{l}\text { Gestational } \\
\text { age }\end{array}$} & 34-36 weeks & 10 & 20 \\
\hline & $37-40$ weeks & 31 & 62 \\
\hline \multirow{3}{*}{$\begin{array}{l}\text { Antenatal } \\
\text { care }\end{array}$} & Nil & 12 & 24 \\
\hline & Irregular & 25 & 50 \\
\hline & Regular & 13 & 46 \\
\hline \multirow{3}{*}{$\begin{array}{l}\text { Period of } \\
\text { onset }\end{array}$} & Antepartum & 29 & 58 \\
\hline & Intepartum & 08 & 16 \\
\hline & Postpartum & 13 & 26 \\
\hline \multirow{3}{*}{$\begin{array}{l}\text { Mode of } \\
\text { delivery }\end{array}$} & $\begin{array}{l}\text { Spontaneous } \\
\text { vaginal(VD) }\end{array}$ & 12 & 24 \\
\hline & $\begin{array}{l}\text { VD with } \\
\text { instrument }\end{array}$ & 21 & 42 \\
\hline & LSCS & 16 & 31 \\
\hline
\end{tabular}

Table 2: Eclamptic patients with CT scan reports.

\begin{tabular}{|llllll|}
\hline Types & $\begin{array}{l}\text { No. of } \\
\text { cases }\end{array}$ & \multicolumn{2}{l}{ Positive CT } & \multicolumn{2}{c|}{ Negative CT } \\
\hline APE & 29 & 16 & $55.17 \%$ & 13 & $44.83 \%$ \\
\hline IPE & 08 & 08 & $100 \%$ & 0 & 0 \\
\hline PPE & 13 & 07 & $53.85 \%$ & 06 & $46.15 \%$ \\
\hline Total & $\mathbf{5 0}$ & $\mathbf{3 1}$ & $\mathbf{6 2 \%}$ & $\mathbf{1 9}$ & $\mathbf{3 8 \%}$ \\
\hline
\end{tabular}

Table 3: Patients with type of lesions.

\begin{tabular}{|llll|}
\hline Lesions & $\begin{array}{l}\text { Positive } \\
\text { cases }\end{array}$ & $\begin{array}{l}\% \text { out of } \\
\text { total } \\
\text { patients } \\
(\mathrm{n}=\mathbf{5 0})\end{array}$ & $\begin{array}{l}\% \text { out of total } \\
\text { CT positive } \\
\text { patients } \\
(\mathbf{n}=\mathbf{3 1})\end{array}$ \\
\hline Edema & 18 & 36 & 58 \\
\hline Infarction & 08 & 18 & 29 \\
\hline Thrombosis & 03 & 06 & 9.68 \\
\hline Haemorrhage & 01 & 02 & 3.26 \\
\hline
\end{tabular}

Table 4: Clinical manifestation vs. distribution of lesion.

\begin{tabular}{|c|c|c|c|c|c|}
\hline Patient no & Occipital lobe & Parietal lobe & Frontal lobe & Basal ganglia & Clinical features \\
\hline 1 & & $\sqrt{ }$ & & & $\mathrm{S}, \mathrm{Dc}, \mathrm{H}$ \\
\hline 2 & & $\sqrt{ }$ & & & S,Dc,H,VD \\
\hline 3 & & $\sqrt{ }$ & & & $\mathrm{S}, \mathrm{Dc}, \mathrm{H}$ \\
\hline 4 & & $\sqrt{ }$ & & & S,Dc,H,VD \\
\hline 5 & & $\sqrt{ }$ & $\sqrt{ }$ & & S,Dc,H,VD \\
\hline 6 & & $\sqrt{ }$ & & & $\mathrm{S}, \mathrm{Dc}, \mathrm{H}, \mathrm{VD}$ \\
\hline 7 & & $\sqrt{ }$ & $\sqrt{ }$ & & $\mathrm{S}, \mathrm{H}$ \\
\hline 8 & & $\sqrt{ }$ & & & $\mathrm{S}, \mathrm{Dc}, \mathrm{H}$ \\
\hline 9 & $\sqrt{ }$ & $\sqrt{ }$ & $\sqrt{ }$ & & $\mathrm{S}, \mathrm{Dc}, \mathrm{H}, \mathrm{VD}$ \\
\hline 10 & & $\sqrt{ }$ & & & $\mathrm{S}, \mathrm{Dc}, \mathrm{H}$ \\
\hline 11 & & & $\sqrt{ }$ & & $\mathrm{S}$ \\
\hline 12 & $\sqrt{ }$ & $\sqrt{ }$ & & $\sqrt{ }$ & $\mathrm{S}, \mathrm{Dc}, \mathrm{VD}$ \\
\hline 13 & & $\sqrt{ }$ & & & $\mathrm{S}, \mathrm{Dc}, \mathrm{H}$ \\
\hline 14 & & $\sqrt{ }$ & $\sqrt{ }$ & & $\mathrm{S}, \mathrm{Dc}, \mathrm{H}$ \\
\hline 15 & & $\sqrt{ }$ & $\sqrt{ }$ & & $\mathrm{S}, \mathrm{Dc}, \mathrm{H}$ \\
\hline 16 & & $\sqrt{ }$ & $\sqrt{ }$ & & $\mathrm{S}, \mathrm{Dc}, \mathrm{H}$ \\
\hline 17 & & $\sqrt{ }$ & & & $\mathrm{S}, \mathrm{Dc}, \mathrm{H}$ \\
\hline 18 & & $\sqrt{ }$ & & & $\mathrm{S}, \mathrm{H}$ \\
\hline 19 & & $\sqrt{ }$ & $\sqrt{ }$ & & S,Dc \\
\hline 20 & & $\sqrt{ }$ & & & $\mathrm{S}, \mathrm{Dc}, \mathrm{H}$ \\
\hline 21 & & & $\sqrt{ }$ & & S,Dc \\
\hline 22 & & & $\sqrt{ }$ & & $\mathrm{S}, \mathrm{Dc}, \mathrm{H}, \mathrm{VD}$ \\
\hline 23 & & $\sqrt{ }$ & & & S,Dc \\
\hline 24 & & $\sqrt{ }$ & $\sqrt{ }$ & & S,Dc,H,VD \\
\hline 25 & & $\sqrt{ }$ & & & S,Dc \\
\hline 26 & & $\sqrt{ }$ & $\sqrt{ }$ & & S,Dc \\
\hline 27 & & $\sqrt{ }$ & $\sqrt{ }$ & & $\mathrm{S}, \mathrm{Dc}, \mathrm{H}$ \\
\hline 28 & & $\sqrt{ }$ & & & $\mathrm{S}, \mathrm{Dc}, \mathrm{H}$ \\
\hline 29 & & $\sqrt{ }$ & & & S,Dc,H \\
\hline 30 & & $\sqrt{ }$ & & & $\mathrm{S}, \mathrm{Dc}, \mathrm{H}$ \\
\hline 31 & $\sqrt{ }$ & $\sqrt{ }$ & & & S,Dc,H,VD \\
\hline Total & $03(9.68 \%)$ & $28(90.32 \%)$ & $13(41.94 \%)$ & $01(3.22 \%)$ & \\
\hline
\end{tabular}

H: headache, S: seizure, DC: depression of consciousness, VD: visual disorder 
Table 5: Distribution of lesion.

\begin{tabular}{|lll|}
\hline $\begin{array}{l}\text { Distribution } \\
\text { of lesion }\end{array}$ & No of cases & $\begin{array}{l}\text { Percentage out of } \\
\text { total CT positive } \\
\text { patients }(\mathbf{n}=31)\end{array}$ \\
\hline Occipital lobe & 03 & $9.68 \%$ \\
\hline Parietal lobe & 28 & $90.32 \%$ \\
\hline Frontal lobe & 13 & $41.94 \%$ \\
\hline Basal ganglia & 01 & $3.22 \%$ \\
\hline
\end{tabular}

Cerebral edema was the most common CT scan finding in patients with Eclampsia followed by cerebral infarction. Thrombosis and haemorrhage were also found, but in less number of cases (Table 3).

Parietal lobe was the most common site $(90.32 \%)$ of pathological changes in brain among patients with eclampsia (Table 4), (Table 5).
CT scan finding was statistically significant in eclamptic patients with visual disorder and depression of consciousness (Table 6). Role of blood pressure in the pathogenesis of CT scan detectable. Cerebral changes were not statistically significant in the study (Table 7).

Table 6: Clinical features with result of CT.

\begin{tabular}{|c|c|c|c|c|c|c|}
\hline \multirow{2}{*}{$\begin{array}{l}\text { Clinical } \\
\text { presentation }\end{array}$} & \multirow{2}{*}{$\begin{array}{l}\text { Total } \\
\text { patients }\end{array}$} & \multicolumn{2}{|c|}{$+\mathrm{CT}$} & \multicolumn{2}{|c|}{ - CT } & \multirow{2}{*}{$\begin{array}{l}\text { P- } \\
\text { value }\end{array}$} \\
\hline & & No & $\%$ & No & $\%$ & \\
\hline Headache & 33 & 23 & 69.7 & 10 & 30.3 & 0.498 \\
\hline $\begin{array}{l}\text { Visual } \\
\text { disorder }\end{array}$ & 5 & 4 & 80 & 1 & 20 & 0.034 \\
\hline $\begin{array}{l}\text { Depression of } \\
\text { consciousness }\end{array}$ & 35 & 28 & 80 & 7 & 20 & 0.03 \\
\hline Seizure & 50 & 31 & 62 & 19 & 38 & 0.56 \\
\hline
\end{tabular}

Table 7: Blood pressure with CT result.

\begin{tabular}{|c|c|c|c|c|c|c|c|}
\hline \multirow{2}{*}{ Blood pressure } & \multicolumn{3}{|c|}{ CT positive } & \multicolumn{3}{|c|}{ CT negative } & \multirow{2}{*}{ P- Value } \\
\hline & Min & Max & Mean士 & Min & Max & Mean士 & \\
\hline SBP (mm Hg) & 130 & 220 & $177 \pm 47.8$ & 120 & 210 & $162 \pm 45.8$ & 0.128 \\
\hline DBP $(\mathrm{mm} \mathrm{Hg})$ & 80 & 150 & $166 \pm 29.3$ & 82 & 140 & $107 \pm 27.7$ & 0.232 \\
\hline Mean BP $(\mathrm{mm} \mathrm{Hg})$ & 97 & 166 & $136 \pm 34.2$ & 95 & 163 & $125 \pm 31.1$ & 0.198 \\
\hline
\end{tabular}

Table 8: Numbers of fits with CT scan finding.

\begin{tabular}{|c|c|c|c|c|}
\hline $\begin{array}{l}\text { Result of } \\
\text { CT }\end{array}$ & $\begin{array}{l}\text { Min no } \\
\text { of fits }\end{array}$ & $\begin{array}{l}\text { Max } \\
\text { no fits }\end{array}$ & Mean \pm 2 sd & $\begin{array}{l}\text { P- } \\
\text { value }\end{array}$ \\
\hline Positive & 04 & 15 & $9.13 \pm 6.2$ & \multirow{2}{*}{0.038} \\
\hline Negative & 03 & 10 & $6.1 \pm 4.04$ & \\
\hline
\end{tabular}

Table 9: Types of lessions with prognosis.

\begin{tabular}{|c|c|c|c|c|c|}
\hline \multirow{2}{*}{$\begin{array}{l}\text { Types of } \\
\text { lesions }\end{array}$} & \multirow{2}{*}{$\begin{array}{l}\text { No of } \\
\text { CT } \\
\text { positive }\end{array}$} & \multicolumn{2}{|c|}{ Recovered } & \multicolumn{2}{|c|}{ Death } \\
\hline & & No & $\%$ & No & $\%$ \\
\hline Edema & 18 & 15 & $83.33 \%$ & 03 & $16.67 \%$ \\
\hline Infraction & 09 & 09 & $100 \%$ & 0 & 0 \\
\hline Thrombosis & 03 & 02 & $66.7 \%$ & 01 & $33.3 \%$ \\
\hline Haemorrhage & 01 & 0 & 0 & 01 & $100 \%$ \\
\hline $\begin{array}{l}\text { Total CT } \\
\text { positive }\end{array}$ & 31 & 26 & $83.87 \%$ & 05 & $16.13 \%$ \\
\hline
\end{tabular}

Number of fits and CT scan detectable cerebral changes had statistically significant relationship with each other in this study (Table 8). Mortality rate was high among eclamptic patients with positive CT scan reports. In the study, none among CT negative patients was died. In the study out of 5 patients died, edema was found in three cases and one each with cerebral thrombosis and cerebral haemorrhage. Average time required for recovery from clinical symptoms in $\mathrm{CT}$ positive and $\mathrm{CT}$ negative eclamptic patients were 42 hours and 26 hours respectively (Table 9).

\section{DISCUSSION}

This study revealed the incidence of eclampsia as 1.8 per 1000 deliveries. Eclampsia was found to be more common among young pregnant women of age group $20-24$ years $(70 \%)$ and mostly in primigravida $(74 \%)$ (Table 1)

Sibai reported $78 \%$ of eclampsia affects women of 20 - 25 years and Dhall (1983) reported primigravidae are to be the worst victims. ${ }^{10}$

Women of term pregnancy (37 - 40 weeks GA) were found to be most commonly affected (62\%) in the study (Table 1). Sibai reported $91 \%$ of eclampsia develops at or beyond 28 weeks. In one study by Mawani (1994), 84.3\% cases were found within 34-40 weeks of pregnancy. ${ }^{10}$

As per the study, fits occurred mostly Antepartum (58\%), $16 \%$ women were in labour and $26 \%$ cases were postpartum (Table 1). Sibai reported similar incidence like $48-53 \%$ were antepartum, $18-36 \%$ patient intrapartum and $11-44 \%$ postpartum. Sibai also stated that there is an increase in the incidence of postpartum women who develop eclampsia beyond 48hours following delivery. $62 \%$ of total eclamptic patients were 
found to be CT positive in our study. CT Scan of brain in $55.17 \%$ patients with antepartum eclampsia, $53.85 \%$ with post partum eclampsia and all patients of intra-partum eclampsia revealed positive findings (Table 2). As the number of intrapartum cases in our study were less, $100 \%$ CT positive among them might be due to sampling error. None of the available literatures has commented on the proportion of eclamptic patients with CT positive except Richards AM, who reported $75 \%$ of unconscious patients with eclampsia were with cerebral changes in their CT Scan. ${ }^{11}$

Most common cerebral findings in CT Scan was found to be edema (58\%) followed by infarction (29\%). $9.68 \%$ of CT positive cases were found with thrombosis and only one woman $(3.26 \%)$ with cerebral haemorrhage (Table 3). Zeeman GG reported edema and infarction among CT positive cases were $93 \%$ and $24.5 \%$ respectively. ${ }^{12}$

Parietal lobe, frontal lobe and occipital lobe were the site of intracranial involvement. Parietal lobe was the commonest site. $90 \%$ of positive cases had cerebral changes in parietal lobe in comparison to frontal lobe (42\%) and occipital lobe (10\%). (Table 4), (Table 5). This finding contradicts the study by Ozgur Dermitas. ${ }^{13}$ They documented $100 \%$ involvement of occipital lobe in comparison to only $9.68 \%$ in the study, but parietal lobe involvement was found to be same $(86 \%)$.

Clinical findings of the patients with/ without CT scan findings were statistically compared. There was statistically significant difference regarding visual disturbance and depression of consciousness, but there was no significant difference regarding headache and seizures (Table 6).

The findings also confirm that eclampsia, like other forms of hypertensive encephalopathy, usually develops with blood pressures well within the range in which autoregulation assures normal blood flow. Specifically, two-thirds of women now described had mean arterial pressures of $120 \mathrm{mmHg}$ or less. ${ }^{13}$ It was found in the study that cerebral edema in eclampsia develops from vascular leakage despite blood pressures well within the usual range of autoregulation. ${ }^{14}$ Meanwhile, multiple seizures occurred more often in those women who presented with higher blood pressures and other evidence of more severe preeclampsia.

In the study, there was no statistically significant difference between blood pressure values of cases with or without CT scan imaging evidence of brain lesions (Table 7). But in cases of eclampsia, brain lesions might occur although blood pressure values are normal but still higher than a patient's routine normal blood pressure. ${ }^{14}$

CT positive eclamptic patients took more times to recover from their clinical symptoms in comparison to CT negative patients
Mortality due to eclampsia in the study was $16.13 \%$ (Table 9).

All the five patients died had positive CT scan. The mortality rate among patients with edema $(16.67 \%)$ was almost equivalent to death rate due to all eclamptic women (Table 9), all the nine women presenting with cerebral infarction were recovered completed, but $100 \%$ mortality was found among patient with cerebral haemorrhage. Out of three patients with thrombosis, two patients recovered, one at Department of Obstetrics and Gynaecology and another one after getting treatment in Neurology Department. The third patient was died. No patient with CT negative results was died.

\section{CONCLUSION}

Eclampsia is a major cause of maternal mortality in India along with haemorrhage and infection. $\mathrm{MgSO}_{4}$ treatment in Eclampsia has shown to reduce morbidity and mortality in many patients and has been proved by many studies. In the study, CT scan is found to be effective in detecting cerebral pathology in more than half of the eclamptic patients. The most common pathological changes detected are cerebral edema and cerebral infarction. Hence neuroimaging methods like CT Scan supports both failure of autoregulation as well as impairment of endothelial function theory in the pathogenesis of eclampsia. Some pathological findings like cerebral thrombosis and intracranial haemorrhage are also found in some complicated eclamptic cases, who don't respond to $\mathrm{MgSO}_{4}$ regimen, remain comatose or show focal neurological symptoms. CT Scan may not be required for the diagnosis of eclampsia, but it must be used in certain complicated patients to detect cerebral pathology at the earliest so that specific management could be provided to reduce the maternal mortality.

\section{Funding: No funding sources \\ Conflict of interest: None declared \\ Ethical approval: The study was approved by the Institutional Ethics Committee}

\section{REFERENCES}

1. Villar MA, Sibai BM. Eclampsia. In: Arias F, editor. Obstetrics and gynaecology clinics of North America. Philadelphia: High Risk Pregnancy; 1988:356-77.

2. Leitch CR, Cameron AD, Walker JJ. The changing pattern of eclampsia over a 60 -year period. $\mathrm{Br} \mathrm{J}$ Obstet Gynaecol. 1997;104:917-22.

3. Mass JL, Lamy C. Stroke in pregnancy in the postpartum period. In: Ginsberg MD, Bogousslavsky J, editors. Cerebrovascular disease: pathophysiology, diagnosis and management. Malden: Blackwell Sciences; 1988:1684-1697.

4. Kanki T, Mihara F, Nakanoh. Diffusion weighted images and vasogenic oedema in pregnancy. Obstet Gynaecol. 1999;93:821-3. 
5. Flankestein JJ, Twickler DM. Cerebral Infarction in eclampsia. Am J Obstet Gynacol. 2002;100:140.

6. Manfredi M, Baltramello A. Eclamptic encephalopathy, neuroimaging and pathological consideration. Acta Neurol Scand. 1997;96:277-82.

7. Swartz RB, Feske SK, Polak JF. Pre-ecalmpsia, eclampsia; clinical and neuroradiological correlates and insights in the pathogenesis of hypertensive encephalopathy. Radiol. 2000;217:317-76.

8. Zhu XW. Cerebral lesions in severe PIH: 61 cases study with computed tomographic scan. Zonghua Chan Ke Za Chi. 1993;28(5):275-7.

9. Iauska DJ. Peripartum stroke and intracranial vascular thrombosis in national hospital admissions. Obstet Gynacol. 1997;89:413.

10. Sibai BM. Diagnosis, prevention, and management of eclampsia. Obstet Gynecol. 2005;105(2):402-10.

11. Richards AM, Moodley J, Graham DI, Bullock MR. Active management of the unconscious eclamptic patient. Br J Obstet Gynaecol. 1986;93(6):554-62.
12. Zeeman GG, Fleckenstein JL, Twickler DM, Cunningham FG. Cerebral infarction in eclampsia. Am J Obstet Gynecol. 2004;190(3):71420.

13. Demirtaş O, Gelal F, Vidinli BD. Cranial MR imaging with clinical correlation in preeclampsia and Eclampsia. Radiol. 2005;11:189-94.

14. Richard Schwartz RB, Feske SK, Polak JF, DeGirolami U, Iaia A, Beckner KM, et al. Preeclampsia-eclampsia: clinical and neuroradiographic correlates and insights into the pathogenesis of hypertensive encephalopathy. Radiol. 2000;217(2):371-6.

Cite this article as: Swain S, Jena PK. Neuroimaging study in eclampsia. Int J Reprod Contracept Obstet Gynecol 2019;8:3550-5. 